\title{
MODELAGEM MATEMÁTICA E FORMAÇÃO SOCIAL DA MENTE: PERSPECTIVAS DE MÚTUO POTENCIAL
}

\section{Maria Alice Veiga Ferreira de Souza}

Instituto Federal do Espírito Santo

E-mail: alicevfs@hotmail.com

\section{OSCAR LUIZ TEIXEIRA DE REZENDE}

Instituto Federal do Espírito Santo

E-mail: oscarltr@gmail.com

\section{LUCIANO LESSA LORENZONI}

Instituto Federal do Espírito Santo

E-mail: Illorenzoni@ifes.edu.br

\section{CAMILA MARIA DIAS PAgUng}

Instituto Federal do Espírito Santo

E-mail: campagung@yahoo.com.br

\section{RESUMO}

A Modelagem Matemática se apresenta como uma via de aprendizagem de objetos matemáticos a partir de ações educacionais que favoreçam a construção de conhecimento pelo aluno de maneira ativa, dialogada e que valoriza e requer a bagagem histórica discente para a estruturação do saber. Para além desse benefício, há outras vantagens silenciosas e menos evidentes, mas de relevo, que devem ser consideradas nessa ação educacional por docentes que, por sua vez, devem se preocupar não apenas com o que seus alunos aprendem, mas, igualmente, com as influências decorrentes sobre a formação social dessas mentes. Esse ensaio discute o potencial educacional da Matemática como modelo de mediação à luz da teoria sociointeracionista de Vigotski e do ciclo de modelagem matemática de Blum e Leiß para a modelagem social de mentes.

\section{PALAVRAS-CHAVE:}

modelagem matemática, formação social, mente, Sociointeracionismo, ciclo da modelagem. 


\title{
MATHEMATICAL MODELING AND SOCIAL FORMATION OF MIND: MUTUAL POTENTIAL PERSPECTIVES
}

\begin{abstract}
:
The mathematical modeling is present as a way of learning mathematical objects from educational activities that promote the knowledge construction by the student in an active way, through dialogue and that values and requires the historical student baggage for the knowledge structuring. In addition to this benefit, there are other quieter and less obvious advantages, but very important, to consider this educational action by teachers who, in turn, must be concerned not only with what their students learn, but also with the influences arising on the social formation of these minds. This assay discuss the educational potential of Mathematics as a mediation model by social interactionist theory of Vygotsky and Blum and Leiß's mathematical modeling cycle for social modeling minds.
\end{abstract}

\section{KEYWORDS:}

mathematical modeling, social formation, mind, sociointeracionism, modeling's cycle.

\section{O CONTEXTO}

O que há na Modelagem Matemática (MM) que possa favorecer a formação social de mentes? Que aspectos presentes em mentes sociais podem beneficiar a formação matemática pela MM? O propósito primeiro deste ensaio é o de analisar a relação e colaboração mútua entre a $\mathrm{MM}$ e a formação social de mentes de estudantes de matemática, como uma via de mão-dupla, nos preocupando, principalmente, com os seguintes aspectos: (1) Identificar as forças emersas do contexto social que possam contribuir para a MM; (2) Reconhecer na MM o potencial para a formação social de mentes de estudantes; (3) Analisar o auxílio mútuo entre teoria de MM e teoria sócio-educacional nas etapas que concretizam a modelagem em Matemática.

Antes de trazermos ao primeiro plano os objetivos mencionados, é útil situarmos o leitor sobre a motivação que subjaz à escrita deste ensaio e que justificam nossas intenções e práticas educacionais e científicas em Educação Matemática, a iniciar pelos resultados de investigações em Educação Matemática 
(SOUZA, 2001, 2013; SOUZA e SIMMER, 2013) e provas de larga escala como a do PISA (Programme for International Student Assessment) que indicam, de modo geral, nível de conhecimento mundial dos estudantes em Matemática aquém dos considerados satisfatórios pela OECD (The Organisation for Economic Co-operation and Development), organismo mundial que fornece indicadores para que os países participantes possam desenvolver políticas educacionais voltadas para o pleno exercício da cidadania em uma sociedade contemporânea.

É fácil verificar que os problemas de aprendizagem são multifatoriais ao considerarmos, pelo menos, a influência de fatores políticos, econômicos e educacionais interferindo sobre esse processo, como apontado pela própria OECD (2015). Pelo lado educacional - nosso interesse particular - a gestão do ensino de conteúdos matemáticos deve estar alinhada com as exigências da sociedade atual que reclama por sujeitos mais autônomos e capazes de participar de contextos diversificados e em constantes transformações impostas pelos complexos sistemas mundiais. O sistema escolar, portanto, possui o desafio de preparar seus alunos para atender a novas demandas sociais, valendo-se de recursos e métodos educacionais que promovam, como propõe Skovsmose (2001), postura crítica e reflexiva.

Estamos falando de ações educacionais que favoreçam a construção do conhecimento pelo aluno de maneira ativa, dialogada e que valorize os "resíduos" trazidos por cada um para essa construção. Há nesses "resíduos" - aqui entendidos como as experiências por eles vividas, conhecimentos anteriores, bagagem cultural, práticas, habilidades e competências internalizadas - apoio que os façam conectar novos conhecimentos aos antigos, ampliando, assim, seu aparato cognitivo, que, por sua vez, será ingrediente para outras construções de conhecimento.

Para Bassanezi (2006), a MM transforma situações da realidade em problemas matemáticos cujas soluções devem ser interpretadas na linguagem usual. Ela vem se 
destacando como uma proposta pedagógica que valoriza a reflexão, a interação com outros indivíduos e o uso dos "resíduos" a partir de situações reais presentes no meio social dos estudantes, utilizando a Matemática como modelo de mediação. Esses aspectos, a propósito, encontram forte respaldo nas teorias sociointeracionistas russas, em especial na de Vigotski. Assim sendo, é possível conceber essa abordagem educacional matemática à luz das premissas de teorias sociointeracionistas que expliquem e fundamentem o potencial educacional ali existente para o ensino e a aprendizagem da Matemática, contribuindo, possivelmente, para a formação educacional requerida pelos sistemas mundiais, cobrados em provas de larga escala e para atuação cidadã no mundo. Eis a importância de se elevar a relação entre a MM como método de ensino e a formação social de mentes.

Ainda a propósito da MM, Kaiser e Sriraman (2006) descrevem uma metaperspectiva denominada modelagem cognitiva - foco de nosso interesse justamente por se preocupar em analisar e entender o processo cognitivo que ocorre durante o processo de modelagem. Além disso, a modelagem cognitiva observa a promoção de processos de pensamento matemático por meio de modelos como imagens mentais ou até mesmo imagens físicas ou enfatizando a modelagem como processo mental, tal como a abstração ou a generalização. Eis a razão de nossa opção por esse olhar da MM, que encontra uma interseção com certos propósitos da teoria vigotskiana, qual seja: estudar alguns aspectos cognitivos da mente humana.

\section{Aspectos ReleVANTES da TEORIA SOCIOINTERACIONISTA DE VIGOTSKI}

Falar na formação de mentes ou visá-la conduz à discussão sobre a relação entre desenvolvimento mental e aprendizagem. Essa relação foi entendida diferentemente por investigadores e que geraram três principais posições, assim discorridas por Vigotski (1998, p.103-109): (1) o desenvolvimento mental é 
independente do aprendizado; (2) a aprendizagem é desenvolvimento; (3) o processo de aprendizagem é um subconjunto do processo de desenvolvimento. Vigotski (1998, p.109-111) rejeitou esses três posicionamentos apresentando a relação atrás mencionada apoiada nos pressupostos de que: (1) qualquer situação de aprendizado, escolar ou não, tem sempre uma história prévia e, (2) o aprendizado deve ser combinado de alguma maneira com o nível de desenvolvimento do indivíduo.

No que diz respeito ao primeiro pressuposto, Vigotski destaca a importância dos "resíduos" ou experiências de vida do indivíduo sendo evocados em momentos de aprendizagem. Nesse sentido, por exemplo, uma criança recém-iniciada em aritmética escolar evoca sua experiência com quantidades.

O segundo pressuposto vigotskiano traz um novo conceito para a relação entre o desenvolvimento e a capacidade de aprendizado: o nível de desenvolvimento real (funções mentais com ciclos de desenvolvimento completados) e o nível de desenvolvimento potencial (funções que não amadureceram ainda e que estão em formação, por isso, dependentes de intervenção externa ao indivíduo e que ocorre no que ficou conhecido como zona de desenvolvimento proximal).

Esses dois pressupostos guardam em si três características marcantes dos estudos de Vigotski $(1993,1998)$ : a cultura, ao lado da linguagem e da relação entre professor e aluno. Isso porque, Vigotski enfatizou as forças externas ao sujeito (as forças da cultura), como o potencial para a aprendizagem humana. Há, portanto, a defesa de que a aprendizagem ocorra, prioritariamente, em um movimento exógeno, ou seja, de fora para dentro do sujeito aprendente, ao contrário de outras concepções como a de Piaget $(1976,1990)$ que a entende como um processo endógeno, ao valorizar aspectos (adaptação - assimilação e acomodação) de dentro para fora. Logo, na perspectiva vigotskiana, o conhecimento é um processo social e 
histórico que decorre da interação do sujeito com a cultura, ou seja, da interação social. O progresso cognitivo ocorre primeiramente no nível social (interpsicológico) para, então, alterar as estruturas individuais (intrapsicológico).

Nessa visão, a cultura (ou culturas) é o embrião para o desenvolvimento cognitivo, sendo reproduzida pelas simbologias e abstrações dos sujeitos, características das funções mentais superiores. Sob essa ótica, a influência cultural possui o poder de formatar as vidas das pessoas dizendo, inclusive, o que devemos aprender e do que necessitamos para nos enquadrarmos àquele grupo ou comunidade - muito disso expresso nas provas de larga escala. Como bem diz Lefrançois (2008, p.266), "as culturas modelam o funcionamento mental humano."

O mundo real na teoria de Vigotski é visto como a mola propulsora para a aprendizagem, que, por sua vez, remete ao pensamento. O pensamento, resultado de um complexo sistema de variáveis, é marcado pela linguagem. A linguagem se caracteriza como uma função mental superior e, portanto, se distancia de aspectos mais práticos para mais abstratos, faculdade que diferencia humanos de outros animais. Temos, no caso deste trabalho, o uso da linguagem corrente - ou materna e da linguagem matemática que devem interagir para a produção de sentido. 0 sentido de uma palavra, para Vigotski (1993, p.125) difere de seu significado, por ser a reunião de todos os eventos psicológicos que ela desperta na consciência do indivíduo. Para ele, "uma palavra adquire seu sentido no contexto em que surge". Souza (2001, p.39) acrescenta que o "universo de significados das palavras a partir do contexto em que estão inseridas é a dinâmica da fala dos indivíduos onde o social ganha especial importância" por ser ele o construtor do psicológico. A linguagem, destarte, funciona como instrumento para a formação das funções mentais superiores. 
O sentido, no entanto, é passível de possíveis ruídos na interação entre as duas linguagens - a corrente e a matemática - podendo gerar obstáculos ou constrangimentos para o fim maior - a modelagem. Mas dizer que devem interagir para uma transposição não significa que a segunda linguagem esteja tão pronta quanto a primeira no processo de modelagem. Nesse sentido, Vigotski (1993) aponta três fases na apropriação da linguagem (seja ela materna ou não), indo de uma fala social a uma fala interior, passando pela egocêntrica, em um continuum, sendo a interior própria de funções superiores. O domínio e a produção de sentido da linguagem cotidiana para a matemática pode ser facilitada - e Vigotski (1993) defende que ela deva ser feita entre humanos - com a interação verbal entre professor-aluno ou aluno-aluno: eis o terceiro eixo de valor para Vigotski - a relação entre humanos, no nosso caso, para a consecução da atividade de MM no ensino e aprendizagem grupais, ao abrir-se espaço de atuação sobre a zona de desenvolvimento proximal e, consequentemente, favorecendo o alcance de funções superiores.

É na zona de desenvolvimento proximal que a ação do outro se destaca, justamente por estar presente uma forte ligação entre o desenvolvimento do indivíduo e sua relação com o meio cultural em que está imerso. A aprendizagem surge nesse ínterim como impulsionadora do desenvolvimento e, assim sendo, cresce a importância do papel da escola em sociedades escolarizadas para a formação social dessas mentes.

\section{O CICLO DE MM DE BLUM E LEIB}

Blum e Leiß (2005) descrevem a MM na forma de um ciclo composto por sete etapas que partem de um mundo real e retornam a ele, passando por um mundo da Matemática (mundo real - mundo da matemática - mundo real): 1- entendimento do problema; 2- simplificação e estruturação; 3- matematização; 4- execução 
matemática; 5- interpretação; 6- validação; 7- apresentação dos resultados. Na Figura 1 temos a representação de uma adaptação desse ciclo de modelagem.

Figura 1: O ciclo de modelagem de Blum e Lei $\beta$ adaptado. Fonte: Blum e Leiß (2005)

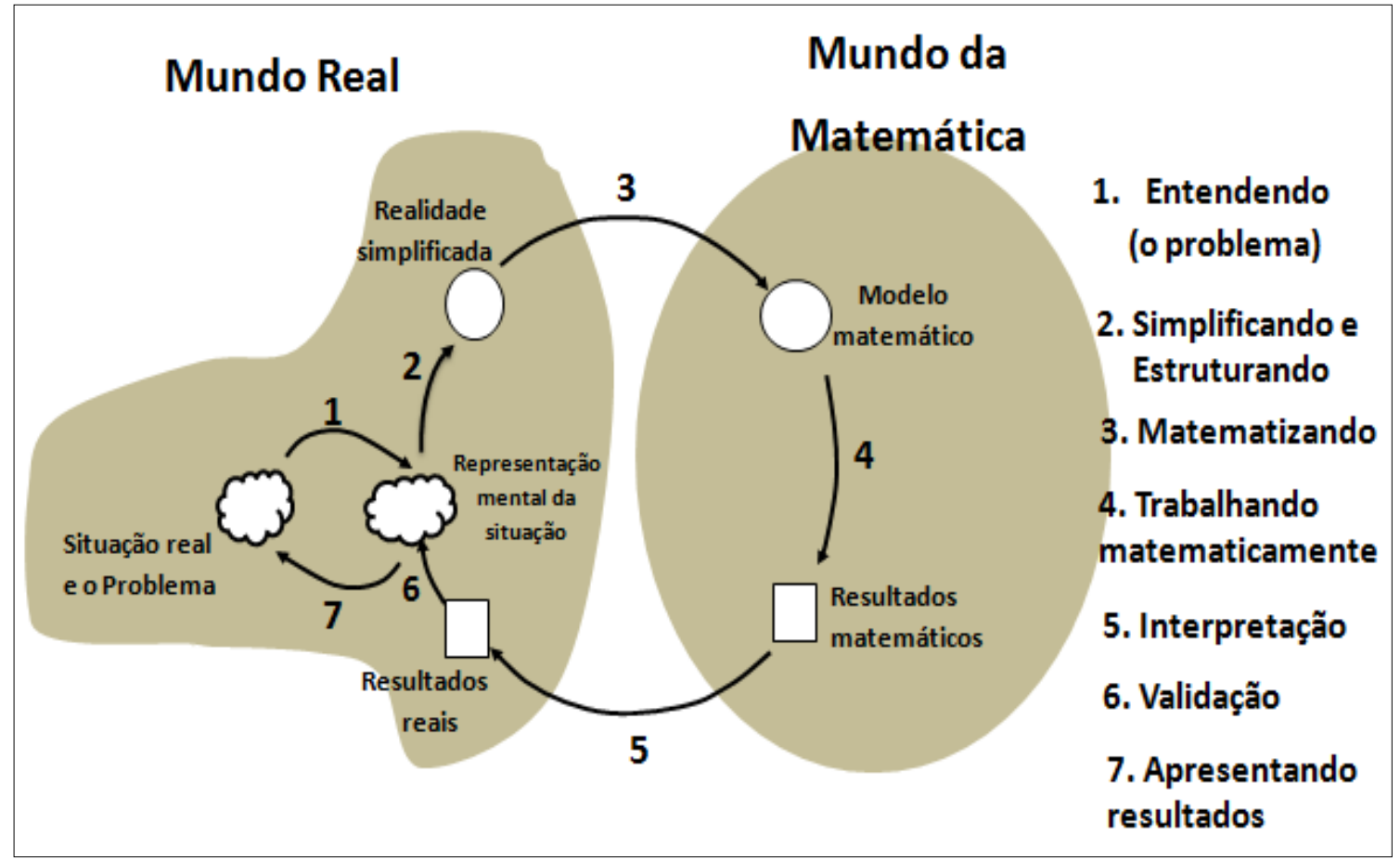

As formas geométricas representam o mundo real (à direita) e o da Matemática (à esquerda), e são traduções do significado de que a MM está relacionada a um dualismo, a uma perspectiva de dois-mundos (SKOVSMOSE, 2001). O mundo real é representado por uma figura geométrica sem uma forma definida, o que reflete o mundo das incertezas, em que podemos operar com a realidade do mundo empírico; por outro lado, o mundo da Matemática é representado por uma figura geométrica, sem arestas e com forma definida, em que podemos operar com conceitos matemáticos como sendo parte do mundo das estruturas, como sugerido pelo formalismo. As etapas transitam inter/entre mundos e constituem uma atividade de MM que descreveremos em tópico particular. Apesar da figura sugerir um ciclo sequencial composto por etapas que pertencem a um mundo e não a outro, na verdade, elas não são estanques a ponto de uma iniciar com o término da outra. Ao contrário, elas se complementam e se alternam no curso do processo de 


\section{DEEDebates

modelagem. Por exemplo, a representação mental da situação, que é como o aprendente entende o problema, ou a realidade simplificada, onde se considera as hipóteses simplificadoras, desencadeiam estímulos cognitivos no sujeito que têm a ver com todas as fases, não sendo exclusivas do mundo real, apesar de estarem ali mais em voga.

\section{O CICLO DA MOdELAGEM E A TEORIA DE VIGOTSKI}

Nesse tópico discutiremos cada uma das sete fases do ciclo adaptado da modelagem com enfoque nos pressupostos da teoria de Vigotski. A ideia é a de analisar o potencial de estudos sociointeracionistas presentes em cada etapa da MM e, vice-versa, ou seja, identificar correlações entre a MM e a formação social de mentes. Vale repetir que a especificidade das discussões em cada etapa são necessárias por questões de análise e para fins didáticos e não porque as fases ocorram separadamente e sequencialmente.

\subsection{ENTENDENDO O PROBLEMA}

Ao escolher ou se deparar com uma situação a ser investigada, extraída do contexto real, deve-se primeiro, entender o problema e os fenômenos observados na realidade. Temos o que se pode denominar de realidade inicial.

Entender um problema requer, inicialmente, selecionar os ingredientes que influenciam significativamente o fenômeno. Envolve identificar o que se tem, reconhecer as condicionantes e fixar o resultado que se quer alcançar. Além disso, o sujeito deve distinguir o que seja relevante do que não seja, em meio a tantas informações.

Ocorre que a modelagem que estamos tratando aqui trabalha com situações emersas de situações reais e essa realidade evoca diferentes visões sobre cada sujeito a partir de sua cultura. Essa diversidade é prevista nos pressupostos 
sociointeracionistas e não poderia ser diferente ao conceber-se o homem como um ser histórico e que se constrói pelas relações com o mundo material e social, ou seja, com sua cultura. A história de vida de cada sujeito - com suas experiências, seus conhecimentos, suas crenças e concepções - pode orientar diferentes entendimentos sobre o mesmo problema. O que um engenheiro civil brasileiro reuniria como elementos para a solução econômica de projetos de casas no Brasil, provavelmente seria diverso de um engenheiro civil com o mesmo problema em algum país da África ou do Polo Norte, pelos contextos culturais diferenciados, além de recursos e outras variáveis de influência.

A cultura, pontualmente por reunir as idiossincrasias cultivadas por uma sociedade - conhecimentos, artes, crenças, leis, morais, costumes, hábitos e aptidões - tem fortes impactos sobre o comportamento cognitivo daqueles que a ela aderem. É condenável no Marrocos que se consuma carne bovina, enquanto no Brasil, não só se consome como se exporta. Essa diferença de concepções pode determinar a conduta dos veterinários brasileiros e marroquinos ao tratar, ambos, do problema de saúde desses animais, sobretudo, porque o primeiro visará à produção leiteira e de corte, direcionando suas ações para esse fim; o segundo visará à longevidade do animal, por idealizarem-no como de estimação. Assim cada indivíduo, de acordo com a sua visão de mundo, pode interpretar e compreender o mesmo problema de modo particular estabelecendo o que se denomina uma representação mental da situação.

Em um movimento contrário, é possível que o trabalho de modelagem desperte nos alunos uma visão de mundo com lentes matemáticas, ampliando e/ou alterando seu modo de ver e entender o contexto em que está imerso. Modelar matematicamente o consumo de água nos vários pontos de uma residência ou verificar o volume de lixo descartável gerado por uma família, por exemplo, pode 


\section{DEE Debates

levá-los a usar a água com maior aproveitamento ou reconhecer a importância da reciclagem para a conservação dos recursos naturais, contribuindo com a formação de mentes sociais.

O comportamento das pessoas revela a cultura do meio. O meio exerce influência sobre o comportamento das pessoas. Logo, o meio é que deve ser modelado, como um dispositivo fornecedor de respostas aos sujeitos alterando seus comportamentos e não o contrário, ou seja, um problema proposto como uma reformulação de um conhecimento.

\subsection{SIMPLIFICANDO E ESTRUTURANDO A REALIDADE}

O problema real selecionado para a investigação deve ser simplificado e estruturado, levando a uma realidade simplificada, que vai direcionar ao modelo matemático.

Os dados colhidos na fase anterior devem passar por um estágio de maturação que inclui verificar se o nível de complexidade do problema é compatível com as possibilidades cognitivas do grupo de sujeitos. Em outras palavras, o aparato cognitivo é chamado ao primeiro plano pela necessidade de verificação de vínculo entre o que se quer e o que se tem. É útil nessa fase responder às perguntas: o que temos?; o que não temos?; o que queremos?; o que não queremos?; o que sabemos?; o que não sabemos? etc. É a fase da abstração em que se busca formular hipóteses simplificadoras do problema, sem perder as informações relevantes coletadas. Por exemplo, pode-se considerar, para efeito de simplificação, em um primeiro recorte, que o processo de fusão para a produção de aço é de tal forma que não há perda de material ou qualquer produção de escória, ou seja, a quantidade de aço produzido é exatamente igual à soma das matérias-primas utilizadas na sua fabricação. Outro exemplo de simplificação comumente adotado é na descrição da 
trajetória de um projétil em que se desconsidera o atrito com o ar e que a ação da força da gravidade independe da sua altura.

O grupo de alunos deve buscar relações entre as informações obtidas na fase anterior sob pena de representarem objetos isolados e com sentidos que não se conectam. A mediação do professor ou de alguém mais experiente, nesse caso, pode fazer diferença ao se poder rastrear elementos do desenvolvimento real como ingredientes de efeito para a laboração na zona de desenvolvimento proximal, levando seus aprendentes ao desenvolvimento potencial nessa etapa da MM.

Nesta perspectiva, Orey e Rosa (2012, p.264) afirmam que esta ação favorece uma transformação, pois procura reduzir o grau de complexidade da realidade, através da escolha de um sistema que possa representá-la adequadamente.

A realidade simplificada pode ser considerada como o que Vigotski denominou de ambiente de mediação, isto é, de intervenção de um elemento intermediário numa relação, que deixa de ser direta e passa a ser intermediada por este elemento (OLIVEIRA, 1993, p.26).

No caso da Modelagem mais especificamente, a realidade simplificada atua como o "interlocutor" entre a realidade inicial, com suas imperfeições e incertezas e o mundo da Matemática, da ciência pura e universal, buscando abstrair os aspectos que são fundamentais para caracterizar a situação problema a partir de um recorte.

\subsection{MATEMATIZANDO}

Nesta etapa faz-se a ponte entre o problema do mundo real com a Matemática, construindo os modelos matemáticos para representar a realidade a partir das hipóteses simplificadoras adotadas.

A busca por uma matematização que expresse a realidade simplificada pode não ser uma reescrita imediata, necessitando, também aqui, da intervenção do 
professor ou de alguém mais experiente. Isso porque, chegar na fase da matematização pode ou não significar alcance das etapas anteriores com sucesso. A dificuldade pode estar em falhas nas fases anteriores ou em conceitos matemáticos avançados em relação à bagagem cultural do grupo. A primeira opção remete ao retorno às fases anteriores; a segunda pode exigir pausa para discussão de conceitos pouco ou ainda não apropriados pelo grupo a fim de ajustá-lo ao nível de desenvolvimento requerido para a modelagem do problema. Ambas as hipóteses carecem da mediação do professor por exigir o pensamento por complexos, ou seja, sair de um cenário social (interpsicológico) para uma circunstância mais abstrata (intrapsicológica), o que se traduz, pela lente de Vigotski, a ir de funções reais para potenciais, como dissemos atrás.

Sendo assim, estabelecido o modelo real e as variáveis que serão manipuladas, o indivíduo passa a dispor do uso de instrumentos oferecidos pela Matemática. Como bem diz Oliveira (1993, p.35), ele deixa de utilizar marcas externas e passa a operar [prioritariamente] com signos internos que representam os objetos do mundo real. Tem início, então, um processo de interiorização semiótica, na qual o aluno abstém-se de realizar operações no plano concreto e passa a atuar no plano das representações mentais.

É o que Vigotski (1998, p. 40-41) chamou de internalização, a reconstrução interna de uma operação externa. Trata-se de um processo interpessoal, desenvolvido primeiro no nível social e, depois, transformado em um processo intrapessoal, ou seja, a nível individual, no próprio sujeito.

\subsection{TRABALHANDO MATEMATICAMENTE}

Nesta etapa o trabalhar matematicamente significa produzir os resultados matemáticos, a partir dos instrumentos que a Matemática pode oferecer. 
Nesse estágio, transita-se plenamente em um mundo ideal, escrito com uma linguagem que não é o de sua cultura natural e, portanto, necessita do outro para sua apropriação. A cultura matemática deve ser apreendida, tal como o da natural, com suas regras, simbologias e idiossincrasias, o que inclui domínio da linguagem apropriada para ali se comunicar. Assim como a natural, o aluno deve ser inserido nessa outra cultura por ser o embrião para a formação de uma mente que vive as diferentes culturas e as relaciona.

No entanto, afirmar que esse estágio esteja completamente em um mundo simbólico diferente do natural, não significa estar inteiramente desligado dos estágios anteriores e nem de sua linguagem natural. Na verdade, há maior preocupação com a matematização do que com outras culturas, mas ainda assim, elas estão presentes, até porque, emergiram da natural.

Nesta etapa do ciclo, o conhecimento científico passa a ser discutido com mais ênfase. O professor indica diretrizes, intermediando o processo, enquanto os alunos buscam nos resíduos (na sua bagagem sociocultural) os conceitos e algoritmos matemáticos úteis para se resolver o problema inicialmente proposto, agora com uso do léxico próprio a delinear o raciocínio. O uso do sistema simbólico para a representação da realidade, conforme a concepção sociointeracionista, permite a comunicação e a interação social necessárias para os avanços na modelagem.

\subsection{INTERPRETAÇÃO}

Com um modelo estabelecido e resolvido é hora de interpretá-lo. A obtenção dos resultados matemáticos requer sua adequação ao modelo matemático. É interpretando, que o aluno vai refletir acerca do comportamento do modelo e seus métodos de resolução na presença da conveniência da solução. À luz da teoria sóciohistórica, revisitar os conceitos matemáticos utilizados na construção do modelo e transpô-lo para o mundo real significa acionar o aparato cognitivo construído na 


\section{DEDebates

Matemática e entendê-lo pela via da realidade. O processo empírico a que foi submetido o aluno e do qual aciona diversas formas de conhecimento científico, pode promover aprendizagens que estimulem o desenvolvimento das funções psíquicas superiores.

\subsection{VALIDAÇÃO}

A validação dos resultados leva o aluno a analisar os resultados obtidos, podendo indicar a necessidade de se percorrer o ciclo novamente. Ela, na verdade, requer a reflexão acerca do comportamento do modelo matemático encontrado e de seus métodos de resolução no contexto extramatemático. O retorno ao mundo real poderá trazer pontos de convergência/divergência entre as representações empírica e sistematizada. Nesse momento, novamente, a atuação do educador sobre a zona de desenvolvimento proximal pode ser relevante, levando-o a ponderar sobre as atividades realizadas. Além disso, esse convite à reflexão sobre sua prática na análise do problema pode ampliar seus conhecimentos ao se "provocar" os estudantes na busca por soluções outras ou ainda melhores e mais simples.

O retorno pode, ainda, subsidiar importantes mudanças sociais nas mentes dos estudantes ao perceberem o mundo pelo alfabeto matemático. Como exemplificamos antes, porventura a MM pode oferecer-Ihes argumentos que os façam alterar seus comportamentos frente ao mundo em que vivem, remodelando socialmente suas mentes.

\subsection{APRESENTAÇÃO DE RESULTADOS}

Na última etapa do ciclo de modelagem, compete ao aluno apresentar suas conclusões a respeito das investigações efetivadas. Ao formular as conclusões será possível constatar a importância da Matemática e da apropriação de sua linguagem não como mero objeto de estudo desligado de significados, mas, ao contrário, como 
um instrumento de leitura do mundo, um mundo de que ele se apropria cada vez que visualiza e compreende suas regras, seus preceitos, suas utilidades, seu jeito de ser - sua cultura - tornando-se membro legítimo. É possível, ainda, que a distância entre a Matemática escolar e a Matemática da vida seja encurtada por uma ponte construída a partir da MM e, em termos vigotskianos, por uma estrutura cognitiva mais rica, que interliga culturas, traduzida não só em aprendizagem, mas em desenvolvimento. Neste momento também a cultura vai se alargando, alterando, pois, as soluções podem formatar o mundo e podem prescrever a realidade dali por diante.

\section{BREVE SÍNTESE}

Destacamos nesse ensaio algumas possibilidades de uso da MM como um instrumento formador de mentes sociais e, reversamente, os "resíduos" presentes nas mentes sociais como potencializadores de uma cultura matemática, em uma perspectiva de mútuo favorecimento.

Vigotski estudou a influência do meio sociocultural na aprendizagem de humanos, marcando um espaço científico que valoriza a história prévia e que respeita o nível de desenvolvimento do indivíduo. A linguagem, a cultura e as interrelações pessoais formam importante tripé para a fundamentação de sua teoria, que podem ser a ponte para criação de ambientes de aprendizagem que edifiquem comportamentos sociais e científicos nos sujeitos.

A escola objetiva educar, o que pressupõe, em seu sentido lato, formar pessoas para o exercício pleno da cidadania, preparando-as para os desafios profissionais e científicos de um mundo em constantes e rápidas transformações. Essa formação inclui a missão de desenvolver comportamentos que façam com que alunos transitem por diferentes culturas, e que as relacione, ampliando, assim, o 
funcionamento mental humano por meio da formulação de problemas, da simplificação, da matematização (no nosso caso), da interpretação e validação para o caso real.

É nesse sentido que a MM pode contribuir para a construção de mentes sociais. E pela visão oposta, a carga social subsidiar uma aculturação matemática, tão carente de consolidações sociais no meio escolar. Essas são algumas implicações e consequências da relação entre $\mathrm{MM}$ e a valorização do meio social para o meio educacional.

\section{REFERÊNCIAS}

BASSANEZI, Rodney Carlos. Ensino-aprendizagem com modelagem matemática: uma nova estratégia. São Paulo: Contexto, 2006.

BLUM, Werner; LEIB, Dominick. "Filling-up" - the problem of independencepreserving teacher interventions in lessons with demanding modelling tasks. Paper for the CERME4, WG 13 Modelling and Application, p. 1623-1633. 2005.

BORROMEO FERRI, Rita. Theoretical and empirical differentiations of phases in the modelling process. Zenttralblatt für Didaktik der Mathematik, v.38(2), 86-95. 2006.

LEFRANÇOIS, Guy. Teorias da aprendizagem. São Paulo: Cengage Learning, 2008.

OCDE - Organisation for Economic Co-operation and Development. Main economic indicators. Data retrieved March 2, 2010 from http://www.oecd-ilibrary.org/.

OLIVEIRA, Marta Kohl. Vygotsky: aprendizado e desenvolvimento, um processo sóciohistórico. São Paulo: Scipione, 1993.

PIAGET, Jean. A equilibração das estruturas cognitivas: o problema central do desenvolvimento. Tradução de Marion Merlone dos Santos Penna. Rio de Janeiro: Zahar, 1976. 
PIAGET, Jean. Epistemologia genética. São Paulo: Martins Fontes, 1990.

ROSA, Milton; OREY, Daniel Clark. A Modelagem como um Ambiente de Aprendizagem para a Conversão do Conhecimento Matemático. Bolema, v. 26, n. 42a , Rio Claro. 2012.

SKOVSMOSE, Ole. Educação Matemática Crítica - a questão da democracia. Campinas: Papirus, 2001.

SOUZA, Maria Alice Veiga Ferreira de. Sistemas lineares na Engenharia: conceito, significados e situação didática. Enseñanza de las Ciencias, v.extra, 3656-3661. 2013.

SOUZA, Maria Alice Veiga Ferreira de. Uma análise de discursos no ensino e aprendizagem de função. 258f. Dissertação de Mestrado em Educação - Programa de Pós-Graduação em Educação, Universidade Federal do Espírito Santo, Vitória, 2001.

SOUZA, Maria Alice Veiga Ferreira de; Simmer, Larissa Martins. Sistemas lineares: do ensino médio às engenharias. Acta Latinoamericana de Matemática Educativa, Buenos Aires, Argentina, 27, julho. 2013.

VIGOTSKI, Lev Semionovich. Pensamento e linguagem. São Paulo: Martins Fontes, 1993.

VIGOTSKI, Lev Semionovich. A formação social da mente. 6.ed. São Paulo: Martins Fontes, 1998.

Recebido em: Agosto de 2017. Publicado em: Agosto de 2017. 